\title{
Influencia de la Temperatura de Conservación sobre la Formación de Histamina en Caballa (Scomber japonicus)
}

\author{
Marta S. Gozzi, María L. Piacente, Virginia Cruces y Edith G. Díaz* \\ Instituto de Tecnología, Facultad de Ingeniería y Ciencias Exactas, Universidad Argentina de la \\ Empresa (UADE), Lima 717, AAO1073, Buenos Aires-Argentina (e-mail: edithgdiaz@uade.edu.ar) \\ * Autor a quien dirigir la correspondencia
}

Recibido Feb. 01, 2011; Aceptado Mar. 15, 2011; Versión Final recibida May. 20, 2011

\begin{abstract}
Resumen
El objeto del presente trabajo fue estudiar la influencia de la temperatura sobre la frescura de la caballa (Scomber japonicus) asociada con los cambios químicos y los atributos organolépticos de los ejemplares conservados en diferentes condiciones. La calidad del pescado se determinó por evaluación sensorial mientras que la inocuidad se estableció midiendo el contenido de histamina a $6{ }^{\circ} \mathrm{C}$ durante una semana realizando el muestreo después de transcurridos uno, tres, cinco y siete días en condiciones de refrigeración. A la temperatura ambiente de $20^{\circ} \mathrm{C}$ el muestreo se efectuó diariamente durante tres días. Las caballas refrigeradas superaron los niveles aceptables de histamina al tercer día antes de ser rechazadas por los panelistas sensoriales. Cuando las muestras se mantuvieron a temperatura ambiente alcanzaron niveles peligrosos de histamina al segundo día en coincidencia con el rechazo determinado por el panel de evaluación sensorial.
\end{abstract}

Palabras clave: histamina, caballa, Scomber japonicus, refrigeración, evaluación sensorial.

\section{Influence of Storage Temperature on Histamine Formation in Mackerel (Scomber japonicus)}

\begin{abstract}
The aim of the present work was to study the influence of storage temperature on the freshness of mackerel (Scomber japonicus) associated with chemical changes and organoleptic attributes of the samples maintained under different environmental conditions. Fish quality was assessed by sensory evaluation while safety was determined through histamine development during refrigerated storage at $6{ }^{\circ} \mathrm{C}$ during a week, sampling for analysis after periods of one, three, five and seven days. At room temperature of $20^{\circ} \mathrm{C}$ samples were analyzed daily during three days. Refrigerated mackerel became unsafe for human consumption, reaching unacceptable histamine levels after three days, before being rejected by the sensory panel. At room temperature samples were discarded due to their high histamine content on the second day, in agreement with the rejection decision of the sensory evaluation panel.
\end{abstract}

Keywords: histamine, mackerel, Scomber japonicus, refrigeration, sensory evaluation 


\section{INTRODUCCIÓN}

La caballa (Scomber japonicus o Scomber japonicus marplatensis), también conocida en América Latina como magrú, cacalina o cachorreta cuyo nombre común en inglés es Chub mackerel pertenece a la familia Scombridae. Se alimenta de organismos del plancton, peces y calamaretes. Tiene un crecimiento rápido y la mayor edad alcanzada es de 13 años. Los ejemplares adultos aparecen en la zona costera de Mar del Plata entre los meses de setiembre a febrero cuando migran para reproducirse y alimentarse intensamente. En el mes de agosto se ha observado la presencia de grandes cardúmenes en la provincia de Buenos Aires y en el norte patagónico. Los desplazamientos de los adultos en la zona costera están condicionados por la temperatura del agua. Cuando en la superficie no se sobrepasan los $20^{\circ} \mathrm{C}$ no se acercan a la costa lo suficiente como para ser accesibles a la flota, condicionando el éxito de las capturas. En invierno la caballa se encuentra en plataforma a una profundidad entre 100 y 200 metros, desplazándose en verano hacia la costa. El número de embarcaciones que actúan sobre este recurso es variable y depende de su disponibilidad y de las necesidades del mercado. En el área marplatense son de rada o de ría. Debido a su pequeño tamaño el área de pesca es muy restringida. El arte de pesca es la lámpara. Antes de cada operación se echa cebo al mar para lograr el ascenso y la concentración de la caballa y hacer efectivo el cerco. En el área "El Rincón" (39 $\left.40^{\circ}-41^{\circ} 30^{\prime} \mathrm{S}\right)$ del Mar Argentino los buques de altura y factoría la capturan con redes de arrastre de fondo (Cousseau y Perrota, 2011). Entre las especies pelágicas la caballa (Scomber japonicus) posee un alto valor nutricional (Stamatis y Arkoudelos, 2007).

Las aminas biógenas son compuestos orgánicos básicos de bajo peso molecular que tienen al menos un grupo amino en su estructura. Se producen por descarboxilación de aminoácidos (Fernández y Álvarez, 2005) o a través de otras vías metabólicas (Kalac y Krausova, 2005). Pueden originarse en procesos de putrefacción por acción de enzimas microbianas a partir de los aminoácidos precursores, por lo que también se consideran indicadores de alteración (Pons Sánchez-Cascado, 2005). Al formarse en los organismos vivos durante el metabolismo normal, están presentes en los alimentos que consumimos habitualmente pudiendo provocar efectos perjudiciales sobre la salud. Es recomendable, por tanto, que el contenido se mantenga por debajo de ciertos límites. La producción de tiramina, histamina, putrescina, cadaverina, agmatina y espermidina se estudió como índice de calidad de la merluza (Merluccius merluccius, L.) conservada en hielo. En esta investigación (Ruiz-Capillas y Moral, 2001) se observó que la concentración de todas la aminas biógenas presentes, excepto la de la espermidina, aumentó progresivamente con el tiempo de almacenamiento, especialmente la de la cadaverina y agmatina, previa a la descomposición del pescado, por lo que estas aminas podrían indicar el estado de frescura de la merluza conservada en hielo. Además, la presencia de las aminas biógenas histamina, tiramina, cadaverina, putrescina, agmatina, espermina y espermidina fue reportada en pescado (Gingerich et al, 2011) presentando la caballa, entre otras especies, un alto potencial para el desarrollo de la histamina a partir de la histidina libre.

La intoxicación escombroide o por histamina se relaciona con el consumo de pescado alterado con un alto contenido de la amina biógena histamina proveniente de la histidina libre por acción enzimática. Presenta síntomas y tratamientos similares a los asociados con las alergias alimentarias (Hungerford, 2010, Gozzi et al, 2008). Algunos estudios (FDA, 2001; Tao et al, 2011) indican que otras aminas como la putrescina y la cadaverina podrían facilitar el transporte de la histamina potenciando su toxicidad. La inadecuada manipulación y conservación del pescado crudo favorecen la contaminación y proliferación de microorganismos, que no solo pueden afectar directamente la salud del individuo, sino también hacerlo de manera indirecta a través de los metabolitos que se forman, como en el caso de la histamina a partir de la histidina. Su contenido en los ejemplares recién capturados es despreciable (Hungerford, 2010), sin embargo, la carga microbiana propia y la incorporada en los procedimientos post-captura encuentran en el pescado un medio excelente para ser colonizado. Las especies pertenecientes a la familia Scombridae, como el atún, la caballa y el bonito, con un alto contenido del aminoácido histidina, precursora de la histamina, sufren este proceso por acción de la enzima histidina descarboxilasa de origen bacteriano. Es importante resaltar que para que se forme histamina tiene que existir histidina libre. $\mathrm{Ni}$ siquiera a partir de los dipéptidos anserina ( $\beta$-alanilmetilhistidina) y carnosina ( $\beta$-alanilhistidina) 
presentes en el músculo y producidos a partir de la histidina, se ha observado la formación de histamina. Existen otras especies no escombroides, como el mahi-mahi, la sardina, el arenque y la anchoa, que también han sido relacionadas con la intoxicación por histamina (Hungerfort, 2010).

Para asegurar la inocuidad, la regulación 2073/2005 de la Comisión Europea (Comission regulation, EC) establece como niveles máximos para las especies de pescados ricos en histidina un valor medio, calculado sobre nueve muestras, no mayor a 100 ppm de histamina, ninguna de las cuales debe exceder 200 ppm. Las pautas señaladas en Estados Unidos por la Administración de Drogas y Medicamentos (FDA/2001) fijan una concentración máxima de histamina, considerando que no se distribuye uniformemente en el pescado, de $50 \mathrm{ppm}$. La mayoría de las especies relacionadas con la intoxicación ha evidenciado valores de histidina libre mayores a 1000 ppm (Hungerford, 2010). Si se considera la estimación de toxicidad de la histamina de 500 ppm señalada por la FDA, una ingestión de $300 \mathrm{~g}$ de pescado alterado susceptible de provocarla correspondería a $150 \mathrm{mg}$ de histamina, que en un individuo de $70 \mathrm{~kg}$ supone una concentración de $2,1 \mathrm{mg} / \mathrm{kg}$ peso corporal. En personas con intolerancia a la histamina debida a causas genéticas, patológicas o farmacológicas, la cantidad tolerable puede ser mucho menor (Vidal Carou, 2007).

Es importante entonces determinar la concentración de histamina en pescado debido al impacto que posee sobre su inocuidad y, por ende, sobre la salud humana (Kose et al, 2011). El método analítico oficial empleado en diferentes países y en la Comunidad Europea (directiva EU/2005) es la cromatografía líquida de alto rendimiento (HPLC). Este procedimiento es costoso para muchas plantas procesadoras de productos pesqueros por lo que ha surgido interés en el desarrollo de equipos portátiles capaces de efectuar una detección rápida de la toxina in situ para aplicaciones regulatorias o de Análisis de Peligros y Puntos Críticos de Control (HACCP) en los programas de calidad. El equipo cuantitativo para la determinación de histamina en alimentos EIA, empleado en el presente trabajo, evidencia una buena correlación y compatibilidad con los resultados obtenidos por el método de HPLC (Kose et al, 2011).

Se ha reportado que la formación de aminas biógenas en el pescado depende de la temperatura, cuya disminución inhibe el crecimiento microbiano y reduce la actividad enzimática (Naila et al., 2010). La producción de histamina a partir de histidina libre es frecuentemente inducida por el abuso de temperatura después de la captura del pescado, ya que los niveles alcanzados dependen principalmente de la combinación de los factores temperatura y tiempo (Guizani et al, 2005). La temperatura óptima observada para el crecimiento de los formadores prolíficos de histamina en caballa, como Morganella morganii y Proteus vulgaris a partir de su precursor histidina, fue de $25^{\circ} \mathrm{C}$ (Kim et al, 2001). Sin embargo, la histamina una vez formada es un compuesto relativamente estable que no se destruye por congelamiento ni por calentamiento o esterilización (Lehane y Olley, 2000). El elemento más importante para impedir su formación es el rápido enfriamiento del pescado inmediatamente después de la captura y su mantenimiento durante el manejo posterior. Con este propósito, algunos países como Estados Unidos y Japón y otros de la Comunidad Europea han establecido regulaciones para la pesca y el procesamiento de productos pesqueros (Tao el al, 2011). El objeto del presente trabajo fue estudiar el efecto de la temperatura sobre la frescura de la caballa (Scomber japonicus marplatensis) asociada con los cambios químicos relacionados con la formación de histamina y la modificación de los atributos organolépticos de los ejemplares conservados en diferentes condiciones.

\section{MATERIALES Y MÉTODOS}

Cuarenta y cinco ejemplares de caballa (Scomber japonicus) fueron adquiridos en un supermercado local de Buenos Aires, Argentina a la hora de apertura del comercio. Los ejemplares analizados fueron capturados mediante sistema de red de cerco aproximadamente entre las latitudes $35^{\circ} 5^{\prime}$ y $45^{\circ} 5^{\prime} \mathrm{S}$ en las cercanías del puerto de Mar del Plata, provincia de Buenos Aires a fines del mes de noviembre. La temperatura ambiente el día de la captura fue de $16^{\circ} \mathrm{C}$. Inmediatamente después de capturadas las caballas se acondicionaron con hielo en cajones de madera de $20 \mathrm{~kg}$. El pescado mantenido en estas condiciones fue rápidamente transportado al laboratorio adonde llegó 36 horas después de su captura en condiciones post- 
rigor. Al arribo, cada uno de los ejemplares fue medido, pesado y evaluado según la frescura a partir de las características sensoriales. Posteriormente cada muestra fue colocada individualmente en una bolsa de plástico limpia y acondicionada adecuadamente. Se eligieron 2 temperaturas: $6{ }^{\circ} \mathrm{C}$ (temperatura de una heladera doméstica) y $20^{\circ} \mathrm{C}$ (temperatura ambiente). Las muestras mantenidas a $6{ }^{\circ} \mathrm{C}$ se analizaron durante un período de siete días mientras que las conservadas a $20^{\circ} \mathrm{C}$ fueron analizadas durante 3 días.

Las cuarenta y cinco caballas se repartieron de la siguiente forma: las conservadas a $6{ }^{\circ} \mathrm{C}$ se distribuyeron en cinco grupos independientes de cinco ejemplares cada uno que fueron analizados individualmente después de transcurridos 1, 3, 5 y 7 días (20 caballas). Los especímenes conservadas a $20^{\circ} \mathrm{C}$ se dividieron en tres grupos de cinco ejemplares como en el caso anterior cuyo análisis individual se realizó al primero, segundo y tercer día (15 caballas). Los análisis correspondientes al día de la compra o día 0 , se realizaron sobre un grupo de cinco ejemplares independientes y los resultados se usaron para ambas temperaturas ( 5 caballas). Para efectuar la comparación por análisis señorial se congelaron cinco ejemplares enteros independientes a $-18^{\circ} \mathrm{C}$ (Paleologos et al, 2004) que fueron presentados descongelados oportunamente a los panelistas sensoriales junto con las muestras a evaluar mantenidas durante $1,3,5$ y 7 días a $6{ }^{\circ} \mathrm{C}$ y durante 2 días a $20^{\circ} \mathrm{C}$. Se emplearon las mismas muestras de referencia para ambas temperaturas los en días 1 y 3 (5 caballas).

\section{Evaluación sensorial}

Para ser categorizado según los términos descriptivos de la Guía para la Calificación de Frescura de la caballa (FAO Fisheries Technical Paper, 1999), el pescado entero, por ser esa la condición en que se comercializa, debe presentar ciertas particularidades. La Tabla 1 describe las características organolépticas correspondientes a las siguientes categorías: E: (extra) pescado fresco de la mejor calidad posible; A: pescado de buena calidad; B: pescado de regular calidad pero todavía apto para el consumo.; C: pescado no apto para el consumo humano. A y B son calidades comerciales. Una calificación por debajo de B hace descartable el pescado para el consumo. El análisis sensorial aplicando este esquema fue realizado por un panel de cuatro evaluadores con la finalidad de asignarle una calificación a cada uno de los especímenes analizados individualmente.

\section{Medición del pH}

Las caballas se filetearon y los filetes limpios se desmenuzaron empleando una procesadora hasta obtener una pasta homogénea. El pH se midió directamente empleando un peachímetro (WTW 526, Alemania). Las determinaciones se realizaron los días 1, 3, 5 y 7 en los especímenes mantenidos a $6{ }^{\circ} \mathrm{C}$ y los días 1,2 y 3 en los conservados a $20^{\circ} \mathrm{C}$. Las muestras control fueron analizadas el día 0.

\section{Determinación de la histamina}

El contenido de histamina se determinó en músculo, por ser esa la parte comestible. Se usó el método de inmunoensayo por absorción ligado a enzimas (Elisa) mediante el equipo cuantitativo para su determinación en alimentos denominado Histamine Food EIA, también conocido como Ridascreen, art. No 1604 distribuido por R-Biopharm Inc., Marshall, USA (suministrado por LDN). Los resultados fueron leídos a $450 \mathrm{~nm}$ usando el lector de microplacas Reader 100, Organon Technica, Miami, Florida, USA. Las determinaciones de histamina en cada ejemplar se realizaron por duplicado.

\section{Análisis estadístico}

Los datos fueron analizados usando el programa Microsoft Office Excel 2003. En el análisis de los resultados fue empleada la descripción estadística del valor medio, desviación estándar, varianza de un factor y prueba t para varianzas de dos muestras. Se usó un nivel de significación del 5\%. 
Tabla 1.Guía para la Calificación de Frescura (caballa)

\begin{tabular}{|c|c|c|c|c|}
\hline & E & A & B & no apto $(C)$ \\
\hline Piel & $\begin{array}{l}\text { Fuertes colores azul } \\
\text { y turquesa; } \\
\text { iridiscencia en todo el } \\
\text { cuerpo; línea lateral } \\
\text { bien definida; } \\
\text { reticulaciones en la } \\
\text { superficie superior; } \\
\text { clara diferenciación } \\
\text { entre la superficie } \\
\text { superior e inferior }\end{array}$ & $\begin{array}{l}\text { pérdida de los } \\
\text { colores brillantes, } \\
\text { palidecimiento de las } \\
\text { reticulaciones; pálido } \\
\text { matiz dorado en la } \\
\text { superficie inferior }\end{array}$ & $\begin{array}{l}\text { matiz dorado } \\
\text { sobre todo el } \\
\text { cuerpo; la piel se } \\
\text { arruga al ser } \\
\text { flexionada; colores } \\
\text { lavados; parches } \\
\text { de iridiscencia }\end{array}$ & $\begin{array}{l}\text { mucus amarillo; } \\
\text { poca diferencia } \\
\text { entre la superficie } \\
\text { superior e inferior }\end{array}$ \\
\hline $\begin{array}{l}\text { Textura del } \\
\text { cuerpo }\end{array}$ & dura & firme & algo blanda & flácido y flojo \\
\hline Ojos & $\begin{array}{l}\text { saltones con lentes } \\
\text { salientes; pupilas } \\
\text { brillantes negro } \\
\text { azabache/azulado } \\
\text { con iris marrón } \\
\text { metálico; } \\
\text { transparentes }\end{array}$ & $\begin{array}{l}\text { convexos; ligera } \\
\text { opacidad de la lente } \\
\text { e iris arrugado; } \\
\text { opacos }\end{array}$ & $\begin{array}{l}\text { planos, lentes } \\
\text { opacos con } \\
\text { pequeñas } \\
\text { manchas negras } \\
\text { en el iris; dorado } \\
\text { pálido }\end{array}$ & $\begin{array}{l}\text { ojos hundidos } \\
\text { cubiertos con } \\
\text { mucus amarillo }\end{array}$ \\
\hline $\begin{array}{l}\text { Apariencia de } \\
\text { las branquias }\end{array}$ & $\begin{array}{l}\text { rojo oscuro/púrpura } \\
\text { uniforme, presencia } \\
\text { de sangre y agua } \\
\text { libre; mucus } \\
\text { transparente }\end{array}$ & $\begin{array}{l}\text { pérdida del color con } \\
\text { mucus rojo/marrón; } \\
\text { márgenes pálidos }\end{array}$ & $\begin{array}{l}\text { acentuada pérdida } \\
\text { del color con áreas } \\
\text { descoloridas; } \\
\text { incremento del } \\
\text { mucus rojo/marrón }\end{array}$ & $\begin{array}{l}\text { decoloración; } \\
\text { mucus grueso y } \\
\text { amarillo }\end{array}$ \\
\hline $\begin{array}{l}\text { Olor de las } \\
\text { branquias }\end{array}$ & $\begin{array}{l}\text { algas de mar frescas; } \\
\text { cortante; halógenos; } \\
\text { pimienta; a grama } \\
\text { recién cortada; } \\
\text { metálico; a sangre; } \\
\text { fresco, aceite dulce }\end{array}$ & $\begin{array}{l}\text { apagado; a lodo; a } \\
\text { humedad; a cartón, a } \\
\text { aceite de pescado }\end{array}$ & $\begin{array}{l}\text { a levaduras; a } \\
\text { fruta agria podrida; } \\
\text { a "perro mojado", } \\
\text { a grama vieja } \\
\text { cortada; } \\
\text { fuertemente } \\
\text { aceitoso }\end{array}$ & $\begin{array}{l}\text { a abono; nabos } \\
\text { podridos; queso } \\
\text { agrio; amoníaco; } \\
\text { sulfuro; aceite } \\
\text { rancio }\end{array}$ \\
\hline
\end{tabular}

\section{RESULTADOS Y DISCUSIÓN}

En la Tabla 2 se describen las características de las caballas analizadas en cada condición. EI peso y la longitud de las caballas se expresan como promedio \pm DS de 5 determinaciones independientes. El tamaño observado permite clasificar los ejemplares como adultos ya que la talla de la primera madurez de los especímenes bonaerenses corresponde a un rango de 24 a 26 centímetros de largo (Perrota et al, 2003). La longitud más frecuente en la captura comercial es de 20 a 45 centímetros (Cousseau y Perrota, 2011).

El rendimiento de cada filete respecto del pescado entero se evaluó individualmente en los 40 ejemplares, luego se calculó el promedio de cada grupo y para expresarlo como rendimiento relativo se asignó el valor de $100 \%$ al rendimiento del grupo correspondiente al tiempo 0 . Los valores obtenidos, a pesar de la disparidad de tamaño de los especímenes, exhiben una tendencia decreciente con la temperatura y el tiempo de conservación (Tabla 2) posiblemente producida por la pérdida de firmeza de la textura muscular acorde con la pérdida de frescura (Shakila et al., 2003). La evaluación sensorial ofrece la ventaja, en el caso particular de las especies frescas, que puede estimar la pérdida de frescura del pescado a partir de su muerte por deterioro autolítico y por acción de la histidina descarboxilasa bacteriana (FAO, Fisheries Technical Paper, 1999). 
Tabla 2. Características de las caballas

\begin{tabular}{|c|c|c|c|c|}
\hline Temperatura & $\begin{array}{c}\text { Tiempo } \\
\text { (días) }\end{array}$ & Peso $(\mathrm{g})$ & Longitud (cm) & $\begin{array}{c}\text { Rendimiento relativo } \\
\text { de los filetes (\%) }\end{array}$ \\
\hline \multirow{4}{*}{$6{ }^{\circ} \mathrm{C}$} & 0 & $418.6 \pm 38.5$ & $36.3 \pm 2.1$ & 100 \\
\cline { 2 - 5 } & 1 & $342.0 \pm 43.8$ & $33.3 \pm 1.7$ & 93 \\
\cline { 2 - 5 } & 3 & $419.4 \pm 90.0$ & $35.7 \pm 2.5$ & 89 \\
\cline { 2 - 5 } & 5 & $400.7 \pm 105.9$ & $35.0 \pm 3.0$ & 86 \\
\hline \multirow{3}{*}{$20^{\circ} \mathrm{C}$} & 1 & $358.4 \pm 19.0$ & $31.1 \pm 9.2$ & 86 \\
\cline { 2 - 5 } & 2 & $671.3 \pm 127.5$ & $41.9 \pm 3.1$ & 75 \\
\cline { 2 - 5 } & 3 & $574.8 \pm 74.1$ & $39.8 \pm 1.0$ & 64 \\
\hline
\end{tabular}

La caracterización de la frescura de cada ejemplar según la especificación de sus propiedades organolépticas se realizó de acuerdo con la Guía para la Calificación de Frescura de la caballa (Tabla 1). Los términos descriptivos constituyen pautas y no todos los rasgos consignados deben estar presentes en forma simultánea en cada muestra analizada. Las cualidades sensoriales de los especímenes analizados, tales como la apariencia, el color y el olor fueron excelentes al comienzo del estudio. Todas las muestras presentaron ojos brillantes, agallas rojas y una firme textura muscular. El panel de evaluadores clasificó al pescado en las condiciones iniciales en la categoría E. En la Tabla 3 los valores de histamina consignados para cada grupo corresponden al promedio de 5 determinaciones sobre ejemplares independientes efectuadas por duplicado y el $\mathrm{pH}$ al promedio de 5 mediciones por grupo. Se indican como $>50$ las caballas que excedieron el límite máximo de 50 ppm fijado por la FDA para la histamina. En la Tabla 3 también se observa que, de acuerdo con la evaluación sensorial, que es indicadora de la frescura, a $6{ }^{\circ} \mathrm{C}$ el deterioro del pescado va en aumento y, aunque al tercer día los ejemplares son clasificados como aptos para el consumo, el contenido de histamina supera el máximo permitido legalmente. Similares resultados fueron reportados por otros autores. Un ejemplo es el caso del atún (Thunnus thynnnus) en el que a los $8^{\circ} \mathrm{C}$ se encontraron niveles de histamina entre 100 y $200 \mathrm{ppm}$ antes de alcanzar el límite de rechazo (López-Sabater et al, 1996). Igualmente los niveles de histamina en el pescado azul anchoa de banco (Pomatomus saltratix) conservado a $5{ }^{\circ} \mathrm{C}$ superaron el valor máximo aconsejado por la FDA antes de alcanzar el 100\% de rechazo (Gingerich et al, 1999).

Estas observaciones indicarían que en las condiciones de refrigeración empleadas en este trabajo, comunes en las heladeras domésticas, no habría que considerar solamente la apariencia física del pescado como criterio para evaluar su toxicidad en relación con el contenido de histamina. Los altos niveles alcanzados en algunos casos en ausencia de indicadores sensoriales de deterioro se deben a que la histamina se puede formar rápidamente por acción de descarboxilasas bacterianas en pescados escombroides y otros que poseen niveles relativamente altos de histidina libre (Lehane y Olley, 2000). Además, después de la muerte los mecanismos de defensa del pescado no inhiben el crecimiento bacteriano y las bacterias productoras de histamina comienzan a crecer y a producirla (FDA, 2001). La proteólisis post-mortem libera histidina adicional a partir de la proteína muscular razón por la cual la concentración de histamina puede alcanzar niveles altos en ausencia de indicadores organolépticos de deterioro (Rossano et al, 2006). Resultados similares fueron reportados en seis especies de pescado importantes comercialmente, incluida la caballa, que fueron analizados en relación con el contenido de histamina y sus características organolépticas además de otros parámetros. Cuando fueron conservadas a la temperatura ambiente de $32{ }^{\circ} \mathrm{C}$ el contenido de histamina no mostró ninguna correlación con los cambios sensoriales producidos. Entre las especies analizadas la caballa demostró superar el límite máximo permitido de 50 ppm después de 12 horas de conservación a $32{ }^{\circ} \mathrm{C}$ pudiendo ocasionar problemas de toxicidad antes de ser organolépticamente inaceptable (Shakila et al., 2003). 
Tabla 3. Cambios producidos en las caballas durante el período de conservación. Calificación inicial de la frescura: $E$. Los valores con letras diferentes en una misma columna, para los 6 y 20 ${ }^{\circ} \mathrm{C}$, son significativamente diferentes $(p<0,05)$.

\begin{tabular}{|c|c|c|c|c|}
\hline \multirow{3}{*}{ Temperatura } & Tiempo (días) & $\begin{array}{c}\text { Concentración de } \\
\text { histamina } \\
(\mathrm{mg} / \mathrm{kg})\end{array}$ & $\mathrm{pH}$ & $\begin{array}{c}\text { Calificación final de } \\
\text { la fresura }\end{array}$ \\
\hline \multirow{5}{*}{$6^{\circ} \mathrm{C}$} & 0 & $3,58 \pm 1,43^{\mathrm{a}}$ & $6,2 \pm 0,1^{\mathrm{f}}$ & $\mathrm{E}$ \\
\cline { 2 - 5 } & 1 & $23,35 \pm 9,10^{\mathrm{b}}$ & $6,1 \pm 0,2^{\mathrm{g}}$ & $\mathrm{A}$ \\
\cline { 2 - 5 } & 3 & $>50^{\mathrm{c}}$ & $6,3 \pm 0,1^{\mathrm{h}}$ & $\mathrm{B}$ \\
\cline { 2 - 5 } & 5 & $>50^{\mathrm{c}}$ & $6,4 \pm 0,2^{\mathrm{i}}$ & $\mathrm{B}$ \\
\hline \multirow{3}{*}{$20^{\circ} \mathrm{C}$} & 7 & $>50^{\mathrm{c}}$ & $6,8 \pm 0,2^{\mathrm{k}}$ & $\mathrm{B}$ \\
\cline { 2 - 5 } & 1 & $1,92 \pm 0.87^{\mathrm{d}}$ & $6,3 \pm 0,2$ & $\mathrm{~B}$ \\
\cline { 2 - 5 } & 2 & $>50^{\mathrm{e}}$ & $6,6 \pm 0,2$ & $\mathrm{C}$ \\
\hline & 3 & $>50^{\mathrm{e}}$ & $6,7 \pm 0,2$ & $\mathrm{C}$ \\
\hline
\end{tabular}

Sin embargo, en discrepancia con estos resultados, en otro estudio se observó que el atún (Thunus albacares) mantenido a $8^{\circ} \mathrm{C}$ fue rechazado por los panelistas a los dos días, antes que el contenido de histamina alcanzara un nivel tóxico (Guizani et al, 2005). En algunos países por precaución sanitaria las regulaciones comerciales establecen que los pescados pelágicos después de tres días de estar a la venta refrigerados deben ser descartados para el consumo (Mbarki et al, 2009).

En la Tabla 3 además se observa que a la temperatura de $6^{\circ} \mathrm{C}$ las caballas categorizadas como $\mathrm{E}$ y A mantienen esa condición hasta el primer día y se descartan luego de los siete, a diferencia de lo reportado en otro pescado escombroide (Trachurus trachurus) que conservado a $0^{\circ} \mathrm{C}$ exhibe esas calificaciones hasta los dos días y es rechazado a los ocho (Losada et al, 2005). En una investigación sobre la caballa del Atlántico (Scomber scombrus, L.) mantenida en hielo se reportó que la vida útil del pescado en su forma vestida alcanza los nueve días, existiendo una correlación entre la evaluación sensorial y la concentración de histamina, además de otros parámetros considerados durante ese período (Jhaveri et al, 1982). Se analizó también el efecto de la temperatura y el tiempo de congelamiento sobre la formación de histamina en la anchoa Engraulis encrasicholus ( $L$, 1758). Mientras muchos estudios señalan que la formación de histamina es insignificante en el pescado conservado a $0^{\circ} \mathrm{C}$ o menos, la información acerca de las condiciones de conservación a temperaturas más elevadas es variable. No se conoce claramente cuál es el límite más bajo de temperatura por encima de los $0^{\circ} \mathrm{C}$ para mantener la inocuidad debido a la gran variedad de poblaciones microbianas entre las especies de pescado. Los resultados indican (Rossano et al, 2006) que a temperaturas mayores a $20^{\circ} \mathrm{C}$ la producción de histamina aumenta notablemente mientras que el congelamiento claramente impide o disminuye la velocidad del proceso.

A las 24 horas de almacenamiento a $20^{\circ} \mathrm{C}$ (Tabla 3 ) las caballas evidencian una leve disminución en el contenido de histamina. Este efecto podría ser atribuido al catabolismo de la amina mediado por enzimas presentes en el músculo del pescado (Kim et al, 2001). Sigue luego (Tabla 3) una rápida formación de histamina que supera a las 48 horas los niveles permitidos por la FDA y que coincide con el rechazo por evaluación sensorial. Con fines de comparación es interesante señalar que en una investigación sobre caballas (Scomber japonicus) mantenidas a $25^{\circ} \mathrm{C}$, el contenido de histamina excedió las $50 \mathrm{ppm}$ el primer día, valor superado recién al segundo día cuando se conservaron a $15^{\circ} \mathrm{C}$. En ambos casos los niveles tóxicos de histamina coincidieron con el rechazo sensorial de los ejemplares (Kim et al, 2001). Esta observación es similar a la reportada para el atún (Thunus albacares) que a las 24 horas de permanecer a $20{ }^{\circ} \mathrm{C}$ fue rechazado por sus características organolépticas y excedió el límite máximo establecido por la FDA para la histamina (Guizani et al, 2005). 
Es aceptado que la formación de histamina en el pescado depende de las bacterias formadoras que a su vez varían con el nivel y la composición de la flora bacteriana. En un estudio sobre caballa (Scomber japonicus) se reportó que los formadores de histamina más prolíficos y prevalentes son Morganella Morganii y Proteus vulgaris y que la temperatura óptima para promover su crecimiento es $25^{\circ} \mathrm{C}$ (Kim et al, 2001). El contenido de histamina de las muestras a $20{ }^{\circ} \mathrm{C}$ (Tabla 3) cuyo nivel aumentó más rápidamente que a $6{ }^{\circ} \mathrm{C}$ guarda una relación directa con el desarrollo de las bacterias implicadas en los procesos de síntesis. La rápida formación de histamina a esta temperatura podría explicarse por el veloz crecimiento de las bacterias mesófilas a $20^{\circ} \mathrm{C}$ (Guizani et al, 2005). También podría atribuirse al incremento de las bacterias formadoras de histidina descarboxilasa, por acción de las enzimas proteolíticas de los fluidos viscerales, cuya actividad aumenta con la temperatura y la presencia de sustratos adecuados (Ayala et al, 2001).

Respecto de los valores de $\mathrm{pH}$ de los filetes de caballa (Tabla 3 ) se observa que aumentan en función del tiempo y la temperatura alcanzando un valor máximo de 6,8 después de mantener los ejemplares a $20{ }^{\circ} \mathrm{C}$ durante tres días y a $6{ }^{\circ} \mathrm{C}$ durante siete. $\mathrm{El} \mathrm{pH}$ varió más rápidamente en el pescado conservado a $20{ }^{\circ} \mathrm{C}$ lo que podría ser atribuido al efecto favorable de la temperatura sobre el crecimiento microbiano (Ayala et al, 2001). Los valores de $\mathrm{pH}$ detallados en la Tabla 3 son similares a los observados por Goulas y Kontominas (2005) quienes reportaron un pH inicial de 6,12 en filetes de caballa (Scomber japonicus) que alcanzó un valor de 6,36 después de seis días de permanecer a una temperatura de $2{ }^{\circ} \mathrm{C}$. También nuestras observaciones son comparables con las publicadas en un estudio sobre el pescado Scomber colias japonicus que evidenció un cambio de $\mathrm{pH}$ en un período de ocho días desde un valor inicial de 5,9 hasta 6,4 a 3 ${ }^{\circ} \mathrm{C}$ y desde 6,0 hasta 6,4 a $6{ }^{\circ} \mathrm{C}$ (Stamatis y Arkoudelos, 2007).

El pH del músculo del pez es cercano a 7 , sin embargo, el valor en el pescado refrigerado puede variar entre 6,0 y 6,5 dependiendo de la especie (Erkan et al., 2006). El incremento de su valor indica la acumulación de compuestos alcalinos tales como el amoníaco, la trimetilamina y otras bases volátiles principalmente derivadas de la acción microbiana (Stamatis y Árkoudelos, 2007). Es importante señalar que aunque la medida de $\mathrm{pH}$ constituye un parámetro de deterioro es muy general y poco sensible.

\section{CONCLUSIONES}

Los resultados obtenidos indican que las caballas mantenidas durante 2 días a la temperatura de $6^{\circ} \mathrm{C}$, frecuente en heladeras domésticas, no presentan problemas para la salud humana porque el contenido de histamina se encuentra por debajo del máximo permitido legalmente. No ocurre lo mismo a la temperatura ambiente de $20{ }^{\circ} \mathrm{C}$, en que los ejemplares deben ser desechados después de las 24 horas para su consumo. Por otra parte, nuestras observaciones advierten que el análisis sensorial no garantiza la inocuidad del producto.

\section{AGRADECIMIENTOS}

El presente trabajo fue financiado con fondos correspondientes al subsidio IT0807 otorgado por el Instituto de Tecnología de la Facultad de Ingeniería y Ciencias Exactas de UADE.

\section{REFERENCIAS}

Ayala, M.E. y otros 4 autores. Patrón de deterioro de anchoveta peruana (Engraulis ringens) almacenada a temperatura de refrigeración. Ciencia y Tecnología de Alimentos 3:161-168 (2001).

Comission regulation (EC) No. 2073/2005 of 15 November 2005 on microbiological criteria for foodstuffs. Off. J. Eur. Union 338: 1-25 (2005).

Cousseau, M.B. y R.G. Perrota, "Atlas de sensibilidad ambiental de la costa y el mar Argentino. Peces. Scomber japonicus". (2007). fecha de consulta: 2 mayo 2011 http://atlas.ambiente.gov.ar/tematicas/mt_02/pdfs/PC_Scomber_japonicus.pdf 
Erkan, N. y otros 4 autores. Spoilage and shelf life of sardines (Sardina pilchardus) packed in modified atmosphere. Eur Food Res Technol 222: 667-673 (2006).

FAO. El pescado fresco: su calidad y cambios de su calidad, "Cambios post-mortem en el pescado". "Guía para la calificación de frescura" EEC in Fisheries Technical Paper (1999). ISSN 1020-6337 [fecha de consulta: 15 octubre 2009]

http://www.fao.org/DOCREP/V7180S/V7180S00.HTM

FDA. "Scombrotoxin (histamine) formation (A chemical hazard)". In Fish and fisheries products hazards and control guidance .Third Edition. Department of Health and Human Services. Center for Food Safety and Apply Nutrition, Office of Sea Food, Washington, DC. (2001).

Fernández García, M. y M.A., Álvarez González. Las aminas biógenas en los alimentos. Revista CTC Alimentación 26: 84-90 (2005).

Gingerich, T .y otros 3 autores "Biogenic amine analysis of fresh stored bluefish and survey of histamine-forming bacteria". Virginia Technology University, Blacksburgh, VA. (2002) [fecha de consulta: 3 mayo 2011]

<http://fshn.ifas.ufl.edu/seafood/sst/26thAnn/file13.pdf>

Gingerich, T. y otros 4 autores. Biogenic amine survey and organoleptic changes in fresh, stored, and temperature-abused bluefish (Pomatomus saltatrix). Journal of Food Protection 62: 1033-1037 (1999).

Goulas, A.E. y M.G., Kontominas. Effect of salting and smoking method on the keeping quality of chub mackerel (Scomber japonicus) biochemical and sensory attributes. Food Chemistry 93: 511520 (2005).

Gozzi, M.S. y otros dos autores. Prevención de la intoxicación escombroide o por histamina en pescado. Ingeniería Alimentaria 73:82-90 (2008).

Guizani, N. y otros 4 autores. The effect of storage temperature on histamine production and the freshness of yellowfin tuna (Thunnus albacares). Food Research International 38: 215-222 (2005).

Hungerford, J.M. Scombroid poisoning. A review. Toxicon 56: 241-243 (2010).

Jhaveri, S.N. y otros 2 autores. Atlantic Mackerel (Scomber scombrus, L.) Shelf Life in Ice. Journal of Food Science 47:1808-1810 (1982)

Kalac, P. y P., Krausova. A review of dietary polyamines: Formation, implications for growth and health and occurrence in foods. Food Chemistry 90: 219-230 (2005).

Kim, S. y otros 4 autores. An. Identification of bacteria crucial to histamine accumulation in Pacific mackerel during storage. Journal of Food Protection 6: 1556-1564 (2001).

Kose, S. y otros 5 autores. Commercial test kits and the determination of histamine in traditional (ethnic) fish products-evaluation against an EU accepted HPLC method. Food Chemistry 125: 1490-1497 (2011).

Leahne, L. y J. Olley. Histamine (Scombroid) fish poisoning. A review in a risk assessment framework. Nationatl Office of Animal and Plant Health. Canberra. (2000).

López Sabater, E.I. y otros 4 autores. Sensory quality and histamine formation during controlled decomposition of Tuna (Thunus thunus). Journal of Food Protection 59: 167-174 (1996).

Losada, V. y otros 3 autores. Inhibition of chemical changes related to freshness loss during storage of horse mackerel (Trachurus trachurus) in slurry ice. Food Chemistry 93: 619-625 (2005).

Mbarki R. y otros 4 autores. Effect of vacuum packaging and low-dose irradiation on the microbial, chemical and sensory characteristics of chub mackerel (Scomber japonicus). Food Microbiology 26: 821-826 (2009). 
Naila, A. y otros 4 autores. Control of Biogenic Amines in Food-Existing and Emerging Approaches. Journal of Food Science 75: R 139-150 (2010).

Paleologos, E. K. y otros 2 autores. Biogenic amines formation and its relation to microbiologicall and sensory attributes in ice-stored whole, gutted and filleted Mediterranean Sea bass (Dicentrarchus labrax). Food Microbiology 21: 549-557 (2004).

Perrota, R.G. y otros diez autores. La caballa Scomber Japonicus y las condiciones del ambiente

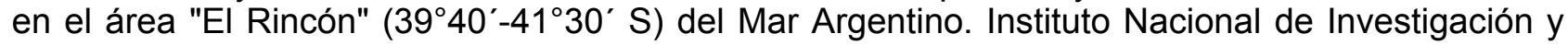
Desarrollo Pesquero (INIDEP) Informe Técnico 54 (2003).

Pons Sánchez-Cascado, S. "Estudio de alternativas para la evaluación de la frescura y la calidad del boquerón (Engraulis encrasicholus) y sus derivados" Tesis de doctorado. Universidad de Barcelona (2005). fecha de consulta: 22 junio 2009

http://www.tdx.cesca.es/TDX-0907105-090359/.

Rossano, R, y otros 3 autores. Influence of storage temperature and freezing time on histamine level in the European anchovy Engraulis encrasicholus (L., 1758): A study by capillary electrophoresis. Journal of Chromatography B, 830:161-164 (2006).

Ruiz-Capillas, C. y Moral, A. Production of biogenic amines and their potential use as quality control índices for hake (Merluccius merluccius, L.) stored in ice. Journal of Food Science 66(7): 1030-1032 (2001).

Shakila, R.J.y otros 2 autores. Changes in histamine and volatile amines in six commercially important species of fish of the Thoothukkudi cost of Tamil Nadu, India stored at ambient temperature. Food Chemistry 82: 347-352 (2003).

Stamatis, N. y J., Arkoudelos. Quality assesment of Scomber japonicus under modified atmosphere and vacuum packaging. Food Control 18: 292-300 (2007).

Tao, Z y otros 4 autores. A survey of histamine content in seafood sold in markets of nine countries. Food Control 22: 430-432 (2011).

Vidal Carou, M. C. "Intolerancia a la Histamina: Una nueva perspectiva para el viejo problema de la histamina y otras amina biógenas en los alimentos". IV Reunión de la Sociedad Española de Seguridad Alimentaria. Universidad de Barcelona (2007). [fecha de consulta: 2 mayo 2010] http://www.sesal.org/documents/Vidal-M-Carmen.pdf. 